\title{
De rerum natura: orígenes y usos de las metáforas biológicas en la teoría archivística clásica
}

\author{
Juan Facundo Araujo*
}

Artículo recibido:

11 de septiembre de 2019

Artículo aceptado:

21 de noviembre de 2019

Artículo de revisión

\section{Resumen}

Este trabajo se propone analizar los antecedentes y fundamentos de las metáforas de índole biológica en la teoría archivística. En primer lugar, se examinará la retórica orgánica como ordenador intelectual para explicitar el Contrato Social moderno presente en Thomas Hobbes, Herbert Spencer y Jean-Jacques Rousseau. La lectura que realiza Michel Foucault sobre este corpus resulta clave para evidenciar esa unión entre la teoría biológica positivista del siglo XIX y el discurso del poder. Posteriormente, procederemos a examinar el impacto de esta metáfora biopolítica en los postulados clásicos de la archivística desde fines del siglo XIX:

* Departamento de Bibliotecología y Ciencia de la Información, Facultad de Filosofía y Letras, Universidad de Buenos Aires, Argentina facund01556@hotmail.com

INVESTIGACIÓN BIBLIOTECOLÓGICA, vol.34, núm. 84, julio/septiembre, 2020, México, ISSN: 2448-8321 pp. 185-202 
la noción del fondo de archivo como un todo orgánico en el Manual Holandés, el documento de archivo como evidencia en Hilary Jenkinson y la teoría del ciclo vital de Theodore Schellenberg.

Palabras clave: Archivo; Orgánico; Biopolítica; Ciclo Vital

De rerum natura: Origins and uses of the biologicals metaphors in classic archive theory

Juan Facundo Araujo

\section{Abstract}

The main purpose of this paper is to analyze the origins of the biological metaphor in the Archive theory. Firstly, the organic rhetoric will be examined as an intellectual method useful to explain the Social contract in Thomas Hobbes, Herbert Spencer and Jean-Jacques Rousseu. A Michel Foucault's approach is a key element to support the union between the nineteenth-century positivist biological theory and discourse of power. Subsequently, of we will proceed to examine the impact of this biopolitical metaphor in the classic postulates of Archival theory: the Dutch Manual, Hilary Jenkinson and Theodore Schellenber's life cycle theory.

Keywords: Archive; Organic; Biopolitics; Life Cycle

Long live the weeds that overwhelm my narrow vegetable realm!

Theodore Roethke, Open House

\section{INTRODUCCIÓN}

\footnotetext{
Como potente figura retórica, la metáfora configura nuevas representaciones conceptuales comprensibles gracias a su efectividad a la hora de reducir la complejidad del mundo, brindar nuevos horizontes interpretativos, establecer hipótesis de lectura y ampliar vocabulario. La metáfora supone una
} 
relación verbal que permite acrecentar el campo de interpretaciones frente a un determinado objeto discursivo.

Cruz Mundet (2011: 21) señala que uno de los paradigmas centrales de la archivística, el life cycle record, relaciona al documento de archivo con la vida similar a un organismo biológico:

El teorema al que hacemos referencia fue enunciado por el archivero Philip Coolidge Brooks en 1940, cuando presentó en la reunión de la Society of American Archivists la ponencia titulada "What records shall we preserve" ("Qué documentos debemos conservar"). En ella introdujo el concepto del "life cycle of records", argumentando el interés legítimo de los archiveros en la creación y gestión de los documentos. Así se creaba uno de los paradigmas de la archivística contemporánea, de enorme influencia hasta nuestros días, que en esencia viene a señalar que el documento tiene una vida similar a la de un organismo biológico, el cual nace (fase de creación), vive (fase de mantenimiento y uso) y muere (fase de expurgo).

Lo orgánico, la unicidad del documento, el ciclo vital, las edades documentales, todos estos términos conforman una parte central del diccionario archivístico. Esta red de significados tiene una genealogía: podemos conjeturar que procede de un discurso atravesado fuertemente por el Contractualismo (un gran acumulador de estas metáforas biológicas). Para Raymond Williams, lo orgánico es una palabra extremadamente difícil, y su historia, complicada. Posee un trascendental uso metafórico que sirve para designar ciertas clases de relación y con ello ciertas clases de sociedad. ${ }^{1} \mathrm{Se}$ gún el autor de Keywords (1976), existen dos tipos de acepciones: dentro de la primera está el uso especializado de la agricultura con sus métodos de cultivo naturales en oposición con los artificiales. Por ende -y ampliando su sentido- para Williams lo orgánico distingue una relación o interrelación significativa entre las partes de una obra: relación orgánica o conexión orgánica. ${ }^{2}$ Aquello que ambas propuestas del afamado crítico británico nos permiten dilucidar es un problema clave de la archivística: ese insistente discernimiento entre fondo de archivo (lo orgánico) y una colección libros (lo artificial).

1 "Orgánico tiene un significado específico en el inglés moderno, para referirse a los procesos o productos de la vida, en los seres humanos, en los animales o en las plantas. También tiene un importante significado aplicado o metafórico, para designar ciertas clases de relación y con ellos ciertas clases de sociedad. En este último sentido es una palabra esencialmente difícil y su historia, en cualquier caso, es excepcionalmente complicada." (Williams, [1976] 2003: 245. Énfasis propio.)

2 “Todavía tienen vigencia otros dos sentidos de orgánico. Está el uso especializado moderno de la agricultura y los alimentos, con el acento puesto en los fertilizantes o métodos de cultivo y crianza naturales en contraposición con los artificiales. [...] Orgánico se ha usado vastamente en las discusiones sobre el arte y la literatura para referirse a una relación e interrelación significativas entre las partes de una obra: relación orgánica o conexión orgánica.” (Williams ([1976] 2003): 247-248. Énfasis propio.) 
Las metáforas biológicas en el interior de la teoría del Contrato son diversas y la disciplina archivística clásica adeuda en cierta manera ese legado. Dentro de la teoría del Pacto, la vida y el cuerpo son tropos repetidos para explicar y justificar el nuevo orden social pensado desde el siglo XVII. Como destaca Gilles Deleuze -discípulo de Michel Foucault-, el Estado en ese periodo se lanza en una verdadera biopolítica y se inventa para sí funciones relacionadas con administrar y controlar la vida. ${ }^{3}$ El Estado es un gestor de los cuerpos de este nuevo pacto. La capacidad simbólica del Estado persigue un resultado efectivo y total, especialmente al resolver las propias asimetrías. La coexistencia antagónica de elementos desiguales puede articularse de forma discursiva gracias a los préstamos contraídos de las metáforas orgánicas. Esta deuda, sentencia Peter Sloterdijk, financia el infortunio que representa el cuerpo vivo como trampa figurativa. ${ }^{4}$ Es pertinente aclarar que Sloterdijk tiene en el marco de sus influencias intelectuales a otros dos filósofos alemanes de gran envergadura: Heidegger y Nietzsche. La suma de estos dos últimos pensadores, más su atractiva prosa, convierten a Sloterdijk en un autor no exento muchas veces de polémica.

Para el especialista italiano en filosofía política Roberto Espósito, quien prosigue el linaje filosófico de Foucault y Deleuze, las categorías biológicas se conforman como un horizonte ontológico ya que el mundo es el contenido de sentido de la vida. ${ }^{5}$ Por ende, la hemorragia de conceptos biologicistas llega al archivo por intermedio de la doctrina del Pacto.

La era de las solidaridades artificiales devenidas del Contrato Social se apoya en la imagen del consenso. La teoría Contractualista conjuga, básicamente, partes que se subordinan para generar un gran todo. El precursor de este modelo fue el pensador inglés Thomas Hobbes. Ese método tan singular, que Hobbes supo entramar con cierta astucia, consistió en aplicar conceptos propios de las ciencias exactas a la filosofía política con el fin último de evadir en sus estudios falsas contradicciones y afirmaciones endebles. La formación escolástica y humanista de Hobbes estuvo fuertemente permeada

3 "Es decir, concibe entre sus funciones una verdadera gestión de la vida: administrar y controlar la vida." (Deleuze, [1985] 2013: 65)

4 "Quizá pueda concluirse del suceso que ciertas oscuridades de la coexistencia son clarificables, en principio, por símiles organismos, como si la idea de la coexistencia antagonistamente cooperadora de elementos disímiles sólo pudiera articularse en una asociación gracias a préstamos tomados de metáforas biológicas compactas. El cuerpo vivo es la trampa figurativa, en la que el primer pensamiento holístico no puede dejar de caer." (Sloterdijk, 2006: 219)

5 "No es a partir de la categoría biológica de vida que se abre la posibilidad de pensar el mundo, sino exactamente lo contrario [...] El mundo no es el receptáculo, o el ambiente circunstante, sino el contenido de sentido de la vida, el único horizonte ontológico a partir del cual ella se nos torna accesible." (Espósito, 2006: 245) 
por los textos de Euclides, Galileo y Kepler. Hobbes cultivó el valor de la retórica, pero no simplemente para "embellecer" o persuadir a sus lectores. Más bien, Hobbes buscó incesantemente la palabra precisa.

En su obra Leviathan, or The Matter, Form and Power of a Common-Wealth Ecclesiasticall and Civil, Hobbes ([1651] 2003) traza su teoría radical donde postula que los individuos declinan enteramente de su propia voluntad en favor del soberano. El Leviatán acapara derechos y aplaca oponentes. La multitud de hombres reunidos bajo un poder común, gracias al ejercicio imaginario de esta (in)voluntaria alianza, es lo que Thomas Hobbes tipifica con letras mayúsculas como CUERPO POLÍTICO. ${ }^{6}$ En un gesto destacadamente irónico, Foucault etiquetará a este Leviatán como un "ogro estatal". Hobbes moldea una tríada conceptual con base en el organismo: la soberanía es el corazón, el soberano es la cabeza y el pueblo se aprisiona en ese amorfo cuerpo político. No obstante, Hobbes no ha sido el único en recurrir a este tropo biológico.

Prosiguiendo con este escenario de aquellos hacedores de la analogía biológica en la esfera político-social, Herbert Spencer se presenta como otro nombre recurrente. Sociólogo y filósofo naturalista británico, Spencer ponderó en un mismo plano de igualdad aquellos mecanismos de la evolución biológica con la sociedad. Su texto más citado en relación a esto es The Principles of Sociology. Allí, naturaliza la sociedad y plantea que el organismo social tiene las mismas prerrogativas y funciones que los organismos vivos. Sin recurrir a complejas alegorías, la sociedad spenceriana se define tangencialmente como un organismo, un conjunto de cuerpos vivos que evolucionan.

Otro carácter de los cuerpos sociales, como de los cuerpos vivos, es que según crecen en tamaño lo hace también su estructura. [...] De esta forma, ya que un organismo vivo puede ser considerado como un conjunto de unidades con vida propia individual, muchas de ellas con un grado considerable de independencia, tendremos menos dificultad en considerar un conjunto de seres humanos como un organismo. (Spencer, [1873] 2004: 435)

En esta perspectiva, no hay diferencia entre el desarrollo de la sociedad y las leyes que regulan la evolución biológica. Jean-Jacques Rousseau -otro de los pilares del Pacto- en su Discours sur l'economie politique no dista mucho

6 "This union so made, is that which men call now-a-days a BODY POLITIC or civil society; and the Greeks call it polis, that is to say, a, city. which may be defined to be a multitude of men, united as one person by a common power, for their common peace, defence, and benefit." (Hobbes, [1640] 2013: 158)

7 "En una palabra, lo que Hobbes quiere eliminar es la conquista e, incluso, la utilización, en el discurso histórico y en la práctica política, de ese problema que es el de la conquista. El invisible adversario del Leviatán es la conquista. En el fondo, ese enorme hombrón artificial que hizo estremecer tanto a los bien pensantes del derecho y la filosofía, el ogro estatal, la enorme silueta que se perfila en la viñeta que abre el Leviatán y que representa al rey con la espada en alto y la cruz en la mano, pensaba bien.” (Foucault, 2000: 94) 
de Spencer y Hobbes. En ese discurso, el filósofo ginebrino nos dice que el cuerpo político es algo semejante al hombre y la anatomía política se compone de la siguiente forma: el poder soberano es la cabeza; las leyes y las costumbres representan el cerebro; los jueces y los magistrados son los órganos de la voluntad y los sentidos; el comercio, la industria y la agricultura serían la boca, la hacienda pública la sangre y la economía el corazón. Finalmente, los ciudadanos son el cuerpo y los miembros que permiten vivir y mover a la gran máquina. ${ }^{8}$

Según esto, pareciese que la multiplicidad de cuerpos diminutos hace funcionar al gran cuerpo político. Rousseau se toma ciertas licencias a la moda de Hobbes y concuerda con la idea del "BODY POLITIC", un préstamo conceptual que tiene más bien aroma a copia. ${ }^{9}$ Ese "bien común" llamado Pacto tiene como referente lo corpóreo, donde el Contrato crea un nuevo organismo, tan semejante a todos nosotros, pero siempre superior e inabordable. El cuerpo indivisible legitima y garantiza la unidad. Los individuos deciden otorgarle a una figura externa el derecho de representarlos total e íntegramente; por ende, el Soberano equivale a esa suma de individuos (representados inmersos en su representante). ${ }^{10}$

8 "Le corps politique, pris individuellement, peut être considéré comme un corps organisé, vivant, et semblable à celui de l'homme. Le pouvoir souverain représente la tête; les lois et les coutumes sont le cerveau, principe des nerfs et siège de l'entendement, de la volonté, et des sens, dont les juges et magistrats sont les organes ; le commerce, l'industrie et l'agriculture, sont la bouche et l'estomac qui préparent la subsistance commune; tes finances publiques sont le sang qu'une sage économie, en faisant les fonctions du cœur, renvoie distribuer par tout le corps la nourriture et la vie; les citoyens sont le corps et les membres qui font mouvoir, vivre et travailler la machine, et qu'on ne saurait blesser en aucune partie, qu'aussitôt l'impression douloureuse ne s'en porte au cerveau, si l'animal est dans un état de santé." (Rousseau, [1755] 2012: 9)

9 "La enunciación de la metáfora orgánica en el texto es tajante, similar a la que encontramos, como pudimos ver anteriormente, en Hobbes o, remontándonos a la antigüedad, en la fábula de Menenio Agrippa: el cuerpo político está configurado como un hombre (antropocentrismo), el soberano se representa como la cabeza del cuerpo (racionalismo), las finanzas públicas son la sangre (liberalismo), los ciudadanos hacen de los miembros del cuerpo en el yo común al todo." (García López, 2016: 746)

10 "No tanto transferir a uno o a varios- una parte de sus derechos o sus poderes. En el fondo, ni siquiera deciden transmitir todos sus derechos. Al contrario, resuelven otorgar a alguien que también pueden ser varios o una asamblea- el derecho de representarlos, total e íntegramente. No se trata de una relación de cesión o delegación de algo perteneciente a los individuos, sino de una representación de los individuos mismos. Es decir que el soberano así constituido equivaldrá íntegramente a los individuos. No tendrá, simplemente, una parte de sus derechos; estará verdaderamente en su lugar, con la totalidad de su poder. Como dice Hobbes, la soberanía así constituida asume la personalidad de todos y con la condición de ese desplazamiento, los individuos así representados estarán presentes en su representante; y por eso mismo, resultará que lo que haga el representante —esto es, el soberano lo hará cada uno de ellos. En cuanto representante de los individuos, el soberano está modelado exactamente sobre ellos. Es, por lo tanto, una individualidad fabricada, pero una individualidad real. El hecho de que ese soberano sea un monarca naturalmente individual no impide que como soberano esté fabricado; y cuando se trata de una asamblea — aunque se trate de un grupo de individuos, no deja de ser menos una individualidad. Esto para las repúblicas de institución. Como pueden ver, en ese mecanismo no hay más que el juego de la voluntad, el pacto y la representación." (Foucault, 2000: 91) 
La biologización de la política, por lo tanto, es una modalidad de relación en el interior de esa serie que Foucault ha denominado "cuerpo-organismo-disciplina-instituciones". Esta serie es el resultado de la unión entre la teoría biológica positivista del siglo XIX y el discurso del poder.

Creo que a partir de ahí pueden comprenderse unas cuantas cosas. Puede entenderse, en primer lugar, el vínculo que se anudó rápidamente -iba a decir inmediatamente- entre la teoría biológica del siglo XIX y el discurso del poder. En el fondo, el evolucionismo, entendido en un sentido amplio -es decir, no tanto la teoría misma de Darwin como el conjunto, el paquete de sus nociones (como jerarquía de las especies en el árbol común de la evolución, lucha por la vida entre las especies, selección que elimina a los menos adaptados)-, se convirtió con toda naturalidad, en el siglo XIX, al cabo de algunos años, no simplemente en una manera de transcribir en términos biológicos el discurso político, no simplemente en una manera de ocultar un discurso político con un ropaje científico, sino realmente en una manera de pensar las relaciones de la colonización, la necesidad de las guerras, la criminalidad, los fenómenos de la locura y la enfermedad mental, la historia de las sociedades con sus diferentes clases, etcétera. (Foucault, 2000: 233)

El Estado concebido orgánicamente tiene su máxima función en la vida del conjunto. La concordia de las solidaridades artificiales es clave para la salud del cuerpo del Estado. La ruptura de esa armonía produce la enfermedad, lo indeseable que el gobernante o el tecnoadministrador de turno deben sanar. La regulación previene ese desfasaje capaz de arruinar el vigor del contrato-cuerpo político. La norma puede aplicarse a escala micro y macro: cuerpos individuales y población. La sociedad estandarizada cubre tanto la norma de la disciplina como la norma de la regulación. Nada se filtra por su coraza; el poder del siglo XIX muerde la vida, la mastica, la procesa, la lleva adentro de su propio cuerpo de ideas y control. El modelo de la peste sobre la lepra triunfa, un proceso histórico importante que Foucault nombra como la "invención de las tecnologías positivas del poder". En su clase del 15 de enero de 1975, Foucault presenta ante su auditorio un modelo de Estado que permite el relevamiento exhaustivo de una población por parte de un poder político. ${ }^{11} \mathrm{El}$ siglo XVIII ha inventado una tecnología perfecta del poder positivo que elabora, observa, sabe y multiplica sus efectos sobre todos los individuos. El poder ha perpetuado la pradera de la transparencia porque

11 "En el fondo, el reemplazo del modelo de la lepra por el modelo de la peste corresponde a un proceso histórico muy importante que, en una palabra, yo llamaría la invención de las tecnologías positivas del poder. [...] La reacción a la peste es una reacción activa; una reacción de inclusión, observación, formación de saber, multiplicación de los efectos de poder a partir de la acumulación de la observación y el saber." (Foucault, 2001:55) 
los actos de gobierno no comulgan con las sombras. El análisis obsesivo, el inventario meticuloso de las partes y la distribución de sujetos "anormales" deben ser explicados de manera que resulte evidente a todos los "apestados" por el control político. Hay que sustentar una pedagogía de lo obvio, elaborar didácticas facilistas para sujetos dóciles que deben comprender el nuevo paisaje de dominación. Para que esto sea efectivo, edificante, la hipérbole naturalista de la teoría del Contrato requiere subyugar la experiencia cotidiana a una serie de abstracciones que siempre cuenten con un claro referente externo. Sloterdijk con precisión destaca que el fantasma del organismo vincula a individuos reales en un todo falseado, grotescamente simplificado. ${ }^{12}$

La vida, esa simplificación, se sitúa en el centro de cualquier procedimiento político. En los inicios del siglo XX, la idea clásica del Estado como conjunto integrado de hombres que se comportan a través de un único individuo espiritual y corpóreo a la vez subsiste en la obra del politólogo Rudolf Kjellen. Es Roberto Espósito quien afirma que este teórico de origen sueco fue probablemente el primero en utilizar el término "biopolítica" (Espósito, 2006: 27). El libro de Kjellen de 1916 titulado Estado como forma de vida (Staten som livsform) vincula una concepción organicista ("la forma viviente" o som livsform) con la matriz del pensamiento político liberal. Espósito (2006: 28) cita a Kjellen para dar cuenta de esa histórica acepción:

Esta tensión característica de la vida misma [...] me ha impulsado a dar a esa disciplina, por analogía con la ciencia de la vida, la biología, el nombre de biopolítica; esto se comprende mejor considerando que la palabra griega «bíos» designa no sólo la vida natural, física, sino tal vez, en medida igualmente significativa, la vida cultural. Esta denominación apunta también a expresar la dependencia que la sociedad manifiesta respecto de las leyes de la vida; esa dependencia, más que cualquier otra cosa, promueve al Estado mismo al papel de árbitro, o al menos de mediador.

El campo semántico de índole biológica permite a la teoría política desligarse de una faceta interpretativa de la realidad porque -justamente- es esa misma realidad la encargada de determinar a la teoría política. La metáfora orgánica moldea y confirma la teoría política. A esto, Espósito (2006: 41) lo va a llamar el "cepo de la biología": "Reconducida a su trasfondo natural, la política queda atrapada en el cepo de la biología sin posibilidad de réplica. La historia humana no es más que la repetición, a veces deforme, pero nunca realmente

12 "Por lo que respecta al organicismo político, pierde, desde el lado opuesto, la diversidad de la especialidad originaria de la coexistencia de seres humanos con sus semejantes y demás. Mientras que la quimera del contrato reúne a individuos falseados y descoloridos en un nexo imaginario, el fantasma del organismo vincula a individuos reales en un todo falseado, grotescamente simplificado.” (Sloterdijk, 2006: 223) 
disímil, de nuestra naturaleza [...] en última instancia, hacer de la naturaleza nuestra única historia”.

La vida, en consecuencia, rellena todo el escenario de una existencia expuesta a las pretensiones del poder que la absorbe y manipula. El hilo conductor de la metáfora de la vida explicita una estrecha relación del Estado con el cuerpo; una política que se constituye a partir de los cuerpos y sobre los cuerpos. En definitiva, la teoría archivística se encuentra subsumida en ese cepo biológico-político donde el Estado liberal se ha asentado con cierta comodidad intelectual. Por consiguiente, el archivo consigna la autoridad del Estado, describe, clasifica y ordena esos registros documentales que dan cuenta de su accionar en el tiempo. La lógica intelectual del archivo es la lógica del Estado. La archivística responde a esa retórica, evidenciado en sus postulados orgánicos este legado metafórico que le ha servido de base argumental, repetido a lo largo de su historia.

\section{El PERIOdO CLÁSICO EN LA TEORÍA ARCHIVÍSTICA: DE LOS “ORGÁNICOS” HOLANDESES AL LIFE CYCLE NORTEAMERICANO}

Varios estudiosos coinciden en un recorte cronológico en el desarrollo evolutivo de la archivística: desde mediados del siglo XIX hasta la década de los 80. Este periodo ha sido denominado Estatista (Cook, 1997), Clásico (Thomassen, 1999) o Histórico-Tecnicista (Ribeiro, 2001). Un año clave de ese periodo inicial es 1898. En la ciudad de Haarlem, tres archiveros holandeses publican el Handleiding voor bet ordenen em baschrijving van Archieve, popularmente conocido como Manual Holandés. Samuel Muller, Johan Feith y Robert Fruin sistematizaron en esta obra una serie de compendios teóricos, creando la primera obra científica de nuestro campo. El trío holandés consolidó metodologías y técnicas para organizar los archivos, iniciando el camino conceptual del principio de procedencia y el orden natural. Feith y Fruin provenían del campo de la abogacía y Muller de la historia. Fueron fundadores de la Sociedad Holandesa de Archivistas y elaboraron este manual en colaboración con el Archivo Nacional Holandés (National Archief) y el Ministerio del Interior. Muller implantó en esta obra sus principales aprendizajes sobre la teoría francesa de archivos adquiridos durante su visita a la Ecole des Chartes parisina en 1873.

La experiencia de los tres autores en el manejo de fondos de archivos medievales y el análisis diplomático de los documentos resultaron fundamentales para diagramar este trabajo. El Manual Holandés está estructurado en seis capítulos en los que se exponen 100 reglas. Esencialmente, los temas que se 
abordan son los siguientes: origen y composición de los depósitos de archivo, disposición y descripción de los documentos, elaboración de inventarios y, finalmente, el uso convencional de términos y signos. Desde el prefacio del manual se advierte lo siguiente: "El libro es tedioso y meticuloso. El lector está avisado". La advertencia de la tríada holandesa es pertinente, ninguna formación discursiva disciplinar suele ser objeto de entretenimiento para el lector. Sin embargo, aquí se manifiesta el objetivo clave que se proponen los holandeses y la finalidad de esta serie de reglas no es otra que organizar y definir un discurso archivístico unívoco. Con su publicación, el surgimiento de un léxico propio brinda la posibilidad de solventar el desarrollo de la ciencia archivística a lo largo de Europa. El Manual Holandés pretendió convertirse en la piedra basal de un campo disciplinar carente de un fuerte consenso teórico y metodológico. Esto se plasma en su estructura de reglas, sectores textuales con la suficiente claridad y fuerza para ordenar conocimientos previos y marcar en un largo plazo los criterios comunes a seguir. De hecho, el reconocimiento de esta obra a nivel mundial vino a través de sus múltiples traducciones: alemán (1905), italiano (1908), francés (1910), inglés (1940) y portugués (1960). La formación académica y profesional de sus autores fueron los archivos públicos, mostrando un evidente sesgo estatal. El principio de procedencia tiene su anclaje en dicho gran Productor, llamado en esta obra Cuerpo Administrativo.

En la actualidad, la primera regla ("El origen de los archivos") nos puede parecer tautológica; sin embargo, en su momento fijó un poderoso procedente. La tríada holandesa define al archivo como todos los documentos, escritos, dibujos y materiales impresos, oficialmente producidos o recibidos por un cuerpo administrativo o una de sus oficinas. De esta primera regla se erige el cimiento donde debe apoyarse toda teoría general de archivos.

La justificación previa a la segunda regla se asocia a una metáfora paleontológica propuesta así por sus autores. El archivista desciende a sus fondos como un investigador de animales prehistóricos que reconstruye el esqueleto del fósil, atento a representarlo, atento a indagar en la forma de esos huesos documentales. Esta analogía impone una idea capital y repetida en la disciplina: lo orgánico como valor de archivo. Así, la regla número dos nos dice que una colección de archivo es un todo orgánico, distinguiendo entre colección y fondo documental. En esta búsqueda de certezas o legalidades disciplinares, la tríada holandesa encuentra en las metáforas biológicas un referente que permita diferenciar su campo de acción. El archivero debe respetar la individualidad de cada fondo de archivo y no alterar su orden original creado así por su productor. El fósil no se rearma con huesos ajenos. El archivero debe permanecer neutral y comprender ese fondo en el marco de ese cuerpo administrativo que lo ha organizado y clasificado de tal forma. 
Desde la regla ocho hasta la 16 se enuncian otros dos pilares fundamentales: el orden original y la integridad del fondo. El primer pilar -justamentedeclara que el archivo tiene una organización original que se corresponde con la organización que le imprimió el cuerpo administrativo que lo produjo. El archivo tiene una coherencia interna, por lo tanto, esa integridad del fondo obstaculiza las clasificaciones artificiales por cronología, temas o geografía. No es necesario generar nuevas clases que subviertan las propias del fondo. El principio de procedencia nace como una invocación divina de la nueva Ciencia de los Archivos, un mantra también alineado con el respect des fonds. Ya en 1841 Natalis de Waily había publicado una circular dentro del Ministerio de Interior de Francia que reemplazaba la anticuada clasificación documental iluminista por materias, temas y lugares.

Ciertamente, el Manual Holandés está influido por las proposiciones científicas del siglo XIX intrínsecamente ligadas con una perspectiva biológica darwiniana. La matriz conceptual de esta obra pretende discriminar una mera arbitraria colección de documentos de un fondo de archivo. El archivo es un "organismo vivo" que crece, se desarrolla y decae con la organización o productor que lo ha creado. La metáfora orgánica justifica la toma de posición y la exclusión de todo aquello que no responda a dicha semántica. Aún más, ese "organismo vivo" llamado archivo, como toda forma de vida dentro de un régimen biopolítico, debe ser respetado y conservado. El fondo de archivo, esa "vida documental", no puede ser desmembrada gracias al mero capricho de una autoridad que así lo imponga. Por eso, la estructura original del archivo debe ser respetuosamente estudiada cuando se la describe y ordena. Los holandeses disponen así de un consenso clasificatorio próximo al productor y lejano a la creación de categorías forzadas por el propio archivero. Los fondos deben permanecer separados y sin la tentación de mezclarlos en pos de series que no le pertenecen, o que no fueron pensadas por su productor. No es de extrañar que el archivista británico Hilary Jenkinson le diese un estatus sagrado al Manual Holandés. Jenkinson lo consideraba la "biblia de los archivos". Es lícito agregar que Jenkinson asienta en su obra enunciados cercanos a un "credo". La metáfora "espiritual" circula también con cierto ímpetu en su entramado discursivo.

En 1922, Jenkinson publica el Manual of Archive Administration, un tratado sobre teoría y práctica archivística, resultado de su trabajo con instituciones y series cerradas y con énfasis en la administración pública. Su manual se compone de una introducción general, seguida de una descripción del origen y desarrollo de los archivos y las normas para guardar documentos, luego teoriza sobre los archivos modernos y las nuevas tendencias de descripción documental y, por último, describe los métodos y mecanismos de producción, 
registro y distribución de los mismos. Concluye su tratado con un abordaje sobre los archivos durante la Primera Guerra Mundial.

Jenkinson postuló una de las ideas claves en el desarrollo de la archivística: la evidencia. Relacionó a los documentos de archivo con la evidencia de los actos de sus productores, un vínculo intrincado entre el registro y su contexto de surgimiento.

The archivist's career is one of service. He exists in order to make other people's work possible [...] His Creed, the Sanctity of Evidence; his Task, the Conservation of every scrap of Evidence attaching to the Documents committed to his charge; his aim to provide, without prejudice or afterthought, for all who wish to know the Means of Knowledge. The good Archivist is perhaps the most selfless devotee of Truth the modern world produces. (Jenkinson, 1922: 106) ${ }^{13}$

El archivero tiene que reverenciar la "verdad", ser un devoto de la misma y evitar falsos atropellos contra esas evidencias. Por consiguiente, no debe caer en la tentación de quebrar este todo orgánico. Este dogma tiene un fuerte sesgo positivista, acentuando el carácter imparcial e incuestionable del documento como fuente para la investigación histórica. La distancia del sujeto con su objeto de análisis resultó una estrategia metodológica que el positivismo promulgó con énfasis y Jenkinson pregonó como válida para el tratamiento de los archivos. Terry Cook cree que Jenkinson quiso -simplemente- imitar en los archivos aquellas bases empíricas del Positivismo historiográfico. En consecuencia, Jenkinson distancia al historiador del archivero. El historiador hurga en el archivo para evidenciar a través de los documentos los procesos históricos y sus "grandes hombres". Su rol es activo: investiga, mientras que al archivero le asigna un rol meramente pasivo: asiste, presencia, nada más. El archivero es un guardián de ese "divino axioma" llamado documento de archivo. Jenkinson se opuso con vehemencia a la intervención en cualquier proceso de selección y clasificación porque los archivos son subproductos naturales de la administración y prueban de manera impoluta sus actos y transacciones.

La selección documental fue otro tema importante para este británico. Al concluir la bestial guerra de trincheras, las administraciones públicas europeas comenzaron a generar grandes volúmenes de registros. Los documentos

13 "La profesión del archivero es de servicio. Él existe con el fin de hacer posible el trabajo de los otros [...] Su Credo, la Santidad de la Evidencia; su tarea, la conservación de cada fragmento de evidencia unida a los documentos entregados a su cargo; su objetivo es proporcionar, sin prejuicios ni ideas adicionales, a todos los que deseen conocer aquellos recursos para su comprensión. El buen archivero es quizás el más devoto desinteresado de la verdad que produce el mundo moderno." (Traducción propia.) 
comenzaban a exceder la capacidad física de su almacenamiento y la pretensión de guardar todas las "evidencias" resultaba impracticable. Era necesario seleccionar y expurgar. No obstante, Jenkinson también excusa de esta tarea al archivero y propone solucionar este escollo según el criterio del productor. El soberano devenido en "Administración Pública Moderna" tiene la responsabilidad de valorar la documentación y el archivero queda así relegado a los fondos cerrados, una postura que recibió numerosas críticas por confiarle demasiado espacio a la capacidad objetiva de la Administración Pública. Ante este panorama, el archivero estilo Jenkinson sólo puede manifestarse como un simple keeper.

Un gran fustigador de las ideas de Jenkinson provino de Kansas y se llamó Theodore Schellenberg. En una carta de 1954 le expresa a un amigo que está cansado que citen a un viejo fósil como autoridad en temas de archivos. La figura paleontológica enunciada previamente por la tríada holandesa parece revivir décadas más tarde en forma de burla. Schellenberg deseaba enterrar así al petrificado Jenkinson y su teoría de la evidencia-objetividad-pasividad del archivero. Ese fue el punto urticante que lo separó de su predecesor británico. Schellenberg es considerado el "padre” de la valoración documental moderna gracias a su pragmatismo norteamericano y su urgencia por remediar la "avalancha de papeles" resultado del New Deal Administration. El teórico norteamericano propuso que los documentos debían tener un valor primario y otro secundario. El primario reflejaría la importancia de los documentos para el productor, mientras que el valor secundario estaría acorde al uso del documento por parte del investigador. Schellenberg empodera al archivero e infla su cotidiana labor con un rol más activo, más allá del refugio medieval complaciente de Jenkinson. La ansiedad del mundo burocrático de la década de los 50 no podía darse el lujo de encadenarse a un remoto pasado de series cerradas.

Como mencionamos anteriormente, los archiveros norteamericanos se enfrentaban a la catástrofe de la "avalancha de los papeles", donde el crecimiento incesante de las tareas administrativas públicas y el atraso en el procesamiento de documentos del gobierno federal llevaron a un colapso archivístico. Ante este panorama de desconcierto, Theodore Roosevelt Schellenberg propone su mentado procedimiento de mejora en Modern Archives: Principles and Techniques (1958). Graduado en Historia por la Universidad de Pennsylvania, perteneció a una creciente generación de laboriosos profesionales asentados en el joven National Archives de Washington D. C., fundado en 1934. Allí, "Ted” Schellenberg aprendió las ventajas de un método pragmático basado en la experimentación, la prueba y el error, la búsqueda de nuevos principios y la puesta en práctica de los mismos. En su visita 
a la ciudad de Córdoba (Argentina) en 1960, el precursor de la Escuela de Archiveros, Aurelio Tanodi, lo describe como un "optimista y un idealista bordeando en lo poético”. En el Archivo Histórico de la provincia mediterránea, Tanodi presencia la siguiente anécdota: un anónimo colega le pregunta a Schellenberg si acaso el trabajo en archivos conlleva a la insania. Ted responde: "Nunca había escuchado tal cosa, pero si he escuchado frecuentemente que algunas personas piensan que el trabajo en un archivo es peligroso para los procesos mentales (hazardous to the mental processes)" ${ }^{14}$ El encanto de la profesión puede residir en una cierta locura, especialmente cuando Schellenberg propone a la comunidad de profesionales su radical teoría de la valoración documental. La fase despreocupada de Jenkinson quedaba así relegada a los anales de la disciplina, los tiempos habían cambiado y la prisa burocrática sacudía al archivero de su aletargada modorra. Schellenberg supo empoderar al gremio de los archiveros, supo otorgarles un nuevo estatus, pese a que tamaña encomienda llegase a desquiciarlos. El archivero debe juzgar la utilidad a futuro que puedan tener los archivos y, para que esto se lleve a cabo efectivamente, debe consultar a los oficiales de la administración o académicos (aclara) evitando así la parálisis frente a una tarea no exenta de nervios y vacilaciones.

Entonces, en resumen, los archivistas deben estar facultados para revisar todos los registros que se propongan destruir por las dependencias gubernamentales. Se les debe señalar la responsabilidad de valorizar los registros para los usos secundarios que puedan tener después de que se hayan agotados [sic] sus usos primarios. Deberán juzgar la importancia de los registros en los términos de utilidad posterior para el pueblo y el gobierno, empleando en ello cualquiera asistencia que pudieran obtener ya sea de los funcionarios públicos o de los especialistas. (Schellenberg, 1958: 61)

La gran jugada metodológica de Schellenberg no se apartó de la metáfora biológica para asentar su pedestal conceptual. Básicamente, la metáfora del ciclo de vida (life cycle) describe la frecuencia de uso de los documentos en diferentes etapas dentro de su evolución “orgánica”. Los documentos se crean, se mantienen, se utilizan, se resguardan temporariamente y tienen una disposición final. Este ciclo oscila entre los grandes universos de lo “activo” y

14 "He had the gift of giving dignity to unattractive work performed in archival agencies. We still remember his reply to a question posed to him in the Archivo Histórico de Cordoba about whether working with archives was unhealthy. "I have never heard that," he replied, but I have beard many times that some people think that archival work is hazardous to the mental processes. Schellenberg succeeded in discovering all the charm of the profession and in publicizing it with the spoken and the written word." (Tanodi, 1970: 199. Énfasis desde el original.) 
lo "inactivo", una distinción emparentada con la idea dual de record (una posible traducción sería documento administrativo) y archive (documento histórico). La formulación teórica alrededor del inicio del documento (origen, creación, nacimiento), su fase intermedia (gestión, actividad, acción, vida) y su final (inactividad, disposición final, muerte) moldeó la práctica cotidiana del archivero ante el fatídico adiestramiento del rigor valorativo. Ante la imposibilidad material de una guarda total, la metáfora del ciclo de vida ha marcado el discurso de la gestión documental (Records Management). El archivero debe participar de todo el ciclo de vida del documento. Es más, debe estar en el momento de la "concepción” del documento. Pero, ¿por qué Schellenberg le asigna al archivero una responsabilidad tan proyectiva? La razón es simple: de esta forma puede determinar y clasificar las series de antemano. El archivero debe anticiparse al archivo, formar parte de su origen.

\section{Conclusiones}

El archivo remite a una técnica de consignación en un lugar de autoridad: el arkheîon o el Estado tiene, frecuentemente, ese destino. En el devenir del accionar de un productor, no importa su origen, los documentos se reúnen. $\mathrm{El}$ archivo es la muestra documental de ese "ahora" que un poder ejercido en un determinado lugar y en una determinada época ha dejado en el tiempo. Cuando la disciplina archivística promulgó sus mandatos para organizar ese arkheîon, una realidad metafórica ajena al archivo estaba en auge. Y, esa realidad de retórica biológica, se filtró en una incipiente teoría archivística. Los autores holandeses supieron construir los fundamentos conceptuales que hoy perduran. Su importancia ha sido clave para distinguir la archivística de la bibliotecología o la museología. El carácter orgánico del fondo de archivo permitió racionalizar ese proceso de distinción de los otros saberes. Metodológicamente, el archivo precisaba diferenciarse, conducir sus formas de abordaje de la práctica archivística de una manera auténtica y única.

Sin embargo, en toda formación disciplinar hay un trazo de opacidad que también es parte de su origen. Es necesario, por ende, revisar su discurso iniciático. Este racconto de metáforas biológicas legadas por los autores de la disciplina archivística parece conducirnos a un "reino natural" de confortable tranquilidad. Allí están los pedestales del quehacer en archivos. ¿También están sus problemas? La sedimentación documentaria de un productor -público o privado- nos hace pensar en un cuerpo sin tinieblas, donde todo está allí y el archivo refleja un orden social imparcial. Pero, el escepticismo de Walter Benjamin nos arruina el Edén teórico que fuimos desplegando hasta 
ahora. Benjamin, promotor de la teoría crítica vinculada con el materialismo histórico de la Escuela de Frankfurt, tuvo el atrevimiento de decirnos que no hay documento de cultura que no sea al mismo tiempo documento de barbarie. Cuidado, alerta en el jardín de las delicias archivístico. Las metáforas biológicas permiten despolitizar la producción, administración, ordenamiento y clasificación del archivo. En el equilibrado jardín de la razón archivística, la hierba mala parece estar disimulada. Pero está allí, existe. No se trata de cuestionar una metáfora orgánica que permitió establecer una terminología homogénea y una metodología con el afán de restarle importancia. Se trata de analizar (o intentar entender) sus orígenes, aplicaciones y fundamentos.

Ante una nueva época que ya mismo está operando en nuestra realidad, ante el dato y su doctrina, toda crítica sigue teniendo importancia y vigencia. El dato se impone, la idea de un algo "inocente" persiste y se repite gracias a los algoritmos matemáticos y los intrincados funcionamientos tecnológicos. Sin embargo, ¿el dato tiene cuerpo? Es sabido que el presente digital quiebra el vínculo entre el soporte y la escritura. Se ha pasado de un concepto de archivo que asociaba soporte, autor, productor, inscripción y sentido a un entramado de datos e informaciones digitales capaces de ser reconfigurados por cualquier sujeto en cualquier momento y lugar. Producto de esta atomización, estamos frente a una nueva concepción del documento, en un escenario de renovados privilegios donde el dato se transforma en la codiciada unidad de información del ahora. En el opuesto a la desmaterialización, la enfermedad nos lleva a pensar la metáfora biológica en un estricto plano de materialidad. El documento analógico tiene un parentesco con un nosotros, ya que lo pueden atacar hongos, insectos variados como termitas, polillas, piojillos de los libros, pececillos de plata, entre otros (nomenclaturas algunas casi borgeanas). El papel también se acidifica y oxida debido a su materialidad intrínseca o por el contacto externo con metales, clips, ganchos. Al documento de archivo hay que conservarlo, cuidarlo, hay toda una dimensión "hospitalaria" alrededor suyo. Un plano de dualidad se juega entonces entre lo sano y lo infectado. Como contraparte, el dato-espectro es demasiado higiénico, aséptico, hasta un poco aburrido. Existen virus en un archivo electrónico, efectivamente, pero su remediación también es del orden del software. La conservación, la restauración, la puesta en valor del patrimonio implica la fragilidad de lo orgánico, la materia que se desgasta y tiende a perderse en el tiempo. Un libro, una carta, una minuta, un legajo, un mapa, a todos estos soportes físicos de la cultura hay que preservarlos del paso de los años y las posibles catástrofes naturales o humanas. Pese a esta descripción de inestabilidades, el papel ha perdurado por mucho más tiempo que cualquier cassette, disco de vinilo, diskette, cd-rom, dvd, Blu-ray, pendrive, etc. Un 
pergamino o un mapamundi sin América están almacenados en un depósito, en una biblioteca, museo o archivo. ¿Dónde están los excesivos archivos humanos subidos mágicamente? Claro, están en la "nube", es decir, en los servidores de las diversas empresas que construyen las mismas. ¿Podremos acceder a esa comulus congestus en 20 o 40 años?

Ante toda novedad surgen siempre vacilaciones, cuestionamientos y nostalgias. Tal vez, ya no precisemos de la usual serie orgánica-biológica para ordenar el paisaje intelectual en torno a los archivos digitales. Quizás en un futuro emerjan nuevas metáforas capaces de representar su inestabilidad, volatilidad o fragilidad. En un díscolo texto de 2001, la historiadora británica Carolyn Steedman sostiene que el polvo es una metáfora de lo perdurable, de lo que circula y nunca desaparece, de algo que se posa en un aquí-ahora y se constituye -de buenas a primeras- en el principio narrativo de la escritura de la historia. El dato carece de polvo, ese contacto único con la suciedad que erosiona lo orgánico. Lo perdurable ya es parte del pasado, una fase superada y en camino a su indeclinable extinción. Lo digital engendrará otras metáforas, sólo resta saber escucharlas y comprenderlas. El poeta latino Lucrecio apeló a suplantar la ignorancia humana a través de su poemario didáctico. ${ }^{15}$ Habrá que esperar un nuevo "Lucrecio" del dato.

\section{REFERENCIAS}

Cook, Terry. 1997. "What is Past is Prologue: a History of Archival Ideas since 1898, and the future paradigm shift". Archivaria 43: 18-63.

Cruz Mundet, José Ramón. 2011. "Principios, términos y conceptos fundamentales”, en Administración de documentos y archivos: textos fundamentales, 15-35. Madrid: Coordinadora de Asociaciones de Archiveros.

Deleuze, Gilles. (1985) 2013. El saber: curso sobre Foucault. Trad. de Pablo Ires, Sebastián Puente. Buenos Aires: Cactus.

Espósito, Roberto. 2006. Bíos. Biopolítica y filosofía. Trad. de Carlo R. Molinari Marotto. Buenos Aires: Amorrortu.

Foucault, Michel. 2000. Defender la sociedad. Trad. de Horacio Pons. Buenos Aires: Fondo de Cultura Económica.

Foucault, Michel. 2001. Los anormales. Trad. de Horario Pons. Buenos Aires: Fondo de Cultura Económica.

García López, Daniel J. 2016. "Fragmentos de la metáfora orgánica en el pensamiento político moderno". Pensamiento 72 (272): 736-760. https://doi.org/10.14422/pen.v72.i272.y2016.014

Hobbes, Thomas. (1640) 2013. The Elements of Law, Natural and Politic. New York: Routledge.

15 De rerum natura o Sobre la naturaleza de las cosas fue escrito en el siglo I a. C. Sus versos tienen esa irreverente y ardua tarea de explicar la realidad del mundo a los otros. 
Hobbes, Thomas. (1651) 2003. Leviathan. London: Penguin.

Jenkinson, Hilary. 1922. A Manual of Archive Administration. Oxford: Clarendon Press.

Moreno, Vivas. 2004. "El tiempo de la archivística: un estudio de sus espacios de racionalidad histórica”. Ciência da Informação 33 (3): 76-96. https://doi.org/10.1590/S0100-19652004000300010

Muller, Franz, Johan Feith y Robert Fruin. (1898) 1940. Manual of the Arrangement and Description of Archives: Draw up by the direction of the Netherlands Association of Archivists. Trad. de Arthur H. Leavitt. New York: H. W. Wilson Company.

Ribeiro, Fernando. 2001. "Archival Science and Changes in the Paradigm". Archival Science 1 (3): 295-310.

Rousseau, Jean-Jacques. (1755) 2012. Discours sur l'économie politique. Paris: La gaya scienza.

Schellenberg, Theodore Roosevelt. 1958. Archivos modernos: principios y técnicas. Trad. de Manuel Carrera Stampa. La Habana: Archivo Nacional Cuba.

Sloterdijk, Peter. 2006. Esferas III: espumas, esferología plural. Trad. de Isidoro Reguera. Madrid: Ediciones Siruela.

Spencer, Herbert. (1873) 2004. “¿Qué es una sociedad? Una sociedad es un organismo”. Trad. de Miguel Beltrán. Reis Revista Española de Investigaciones Sociológicas 107: 231-243.

Steedman, Carolyn. 2001. Dust. Manchester: Manchester University Press.

Tanodi, Aurelio. 1970. "In Memoriam: Theodore Schellenber". The American Archivist 33 (2): 190-202.

Thomassen, T. 1999. "The Development of Archival Science and its European Dimension", en The Archivist and the Archival Science Seminar for Anna Christina Ulfsparre, 67-74. Lund: Landsarkivet.

Williams, Raymond. (1976) 2003. Palabra clave: un vocabulario de la cultura y la sociedad. Trad. de Horacio Pons. Buenos Aires: Nueva Visión.

Para citar este texto:

Facundo Araujo, Juan. 2020. "De rerum natura: orígenes y usos de las metáforas biológicas en la teoría archivística clásica”. Investigación Bibliotecológica: archivonomía, bibliotecología e información 34 (84): 185-202. http://dx.doi.org/10.22201/iibi.24488321xe.2020.84.58171 